\title{
Molecular transformation of natural and anthropogenic dissolved organic matter under photo-irradiation in the presence of nano $\mathrm{TiO}_{2}$
}

\author{
Jitao Lv ${ }^{a}$, Dan Li ${ }^{\mathrm{b}}$, Lei Luo ${ }^{\mathrm{a}}$, Tong Wu ${ }^{\mathrm{b}}$, Shuzhen Zhang ${ }^{\mathrm{a}, \mathrm{c}, \text { * }}$ \\ a State Key Laboratory of Environmental Chemistry and Ecotoxicology, Research Center for Eco-Environmental Sciences, Chinese Academy of Sciences, \\ Beijing 100085, China \\ ${ }^{\mathrm{b}}$ School of Environmental Science and Engineering, Hebei University of Science and Technology, Hebei, 050018, China \\ ${ }^{\mathrm{c}}$ University of Chinese Academy of Sciences, Beijing, 100049, China
}

\section{A R T I C L E I N F O}

\section{Article history:}

Received 24 March 2017

Received in revised form

23 August 2017

Accepted 23 August 2017

Available online 26 August 2017

\section{Keywords:}

Dissolved organic matter (DOM)

Sewage sludge

Peat

Photo-transformation

$\mathrm{TiO}_{2}$

FT-ICR-MS

\begin{abstract}
A B S T R A C T
Photochemical transformation of dissolved organic matter (DOM) plays a very important role in the cycling of organic carbon in aquatic systems. Increasing release of photoactive nanoparticles such as titanium dioxide nanoparticles (nano $\mathrm{TiO}_{2}$ ) into surface water may impact this process. The present study employed Fourier transform ion cyclotron resonance mass spectrometry (FT-ICR-MS) to examine the molecular transformation of natural DOM (peat DOM, DOM $\mathrm{p}_{\mathrm{p}}$ ) and anthropogenic DOM (sludge-derived $\mathrm{DOM}, \mathrm{DOM}_{\mathrm{s}}$ ) under photo-irradiation as affected by nano $\mathrm{TiO}_{2}$. Differences in molecular components between $\mathrm{DOM}_{\mathrm{p}}$ and $\mathrm{DOM}_{\mathrm{s}}$ were observed. $\mathrm{DOM}_{\mathrm{s}}$ contained more heteroatom formulas (76\%) with low aromaticity and low carbon oxidation state than did $\mathrm{DOM}_{\mathrm{p}}(22 \%)$. The presence of nano $\mathrm{TiO}_{2}$ resulted in significant decreases in both DOM content and molecular diversity under photo-irradiation. Consistent alterations were observed between $\mathrm{DOM}_{\mathrm{p}}$ and $\mathrm{DOM}_{s}$ such that high molecular weight compounds, high aromaticity and/or heteroatom S-containing compounds were more easily photodegraded in the presence of nano $\mathrm{TiO}_{2}$; whereas the average carbon oxidation state decreased in $\mathrm{DOM}_{\mathrm{p}}$ but increased in $\mathrm{DOM}_{\mathrm{s}}$, likely due to the significant differences in $\mathrm{O}$ abundance, especially in the contents of carboxyl moieties, between $\mathrm{DOM}_{\mathrm{p}}$ and $\mathrm{DOM}_{\mathrm{s}}$. The findings of the present study suggest that the release of nano $\mathrm{TiO}_{2}$ into aquatic environment will accelerate the consumption of dissolved organic carbon and the attenuation of molecular diversity for both DOM in waters.
\end{abstract}

๑) 2017 Elsevier Ltd. All rights reserved.

\section{Introduction}

Among the commercially available engineered nanoparticles (NPs), titanium dioxide nanoparticles (nano $\mathrm{TiO}_{2}$ ) are the most widely used engineered nanomaterials to date (Troester et al., 2016). Nano $\mathrm{TiO}_{2}$ materials have been produced on a large scale for applications in pigments, coatings, and sunscreen cosmetic additives, as well as environmental applications such as removal of various contaminants in water, air and soils by adsorption and/or photo-catalytic degradation (Lee and Choi, 2002; Luo et al., 2010; Pena et al., 2006; Zhang et al., 2007). As a result, the release of nano $\mathrm{TiO}_{2}$ into the environment is unavoidable, particularly into waters, and the amount will continue to increase (Klaine et al.,

\footnotetext{
* Corresponding author. Research Center for Eco-Environmental Sciences, Chinese Academy of Sciences, P. O. Box 2871, Beijing 100085, China.

E-mail address: szzhang@rcees.ac.cn (S. Zhang).
}

2008; Nowack and Bucheli, 2007). Therefore, the contents of nano $\mathrm{TiO}_{2}$ in waters are expected to be much higher than other engineered nanoparticles (Gottschalk et al., 2010, 2009). Model studies have predicted that the production of nano- $\mathrm{TiO}_{2}$ would exceed 2.5 million tons per year by 2025 (Robichaud et al., 2009). Once released into waters, nano $\mathrm{TiO}_{2}$ will interact with dissolved organic matter (DOM), which universally exists in natural water. In the past few years, many researchers have demonstrated that DOM plays a critical role in the stability and mobility of NPs, including nano $\mathrm{TiO}_{2}$, in aquatic environments (Domingos et al., 2009; Aiken et al., 2011; Zhu et al., 2014; Adam et al., 2016). These studies have demonstrated that the bond of DOM on nano $\mathrm{TiO}_{2}$ will significantly reduce the aggregation of nanoparticles in aqueous systems. Therefore, the presence of DOM will not only enhance the mobility but also impact the distribution of nano $\mathrm{TiO}_{2}$ in waters.

Another important fact is that $\mathrm{TiO}_{2}$ is a photoactive nanomaterial. Studies have demonstrated that $\mathrm{TiO}_{2}$-based photocatalytic oxidation can induce the destruction of natural organic 
matters (Eggins et al., 1997; Li et al., 2002; Liu et al., 2008a, 2008b; Wiszniowski et al., 2003). Most of these studies attempted to monitor the changes in concentration and spectral features of dissolved organic carbon (DOC) in waters in the presence of nano $\mathrm{TiO}_{2}$. Some investigated the changes in the molecular weight and hydrophobic fractions of DOM by using size exclusion chromatography (SEC) and resin fractionation (Liu et al., 2008a, 2008b; Wu et al., 2016). However, these analytical techniques failed to clarify the photocatalytic transformation of DOM at the molecular scale. The great advance in high-resolution mass spectroscopy technique namely electrospray ionization coupled with Fourier transform ion cyclotron resonance mass spectrometry (ESI-FT-ICR-MS) provided the unique opportunity to detect thousands of individual molecules in DOM (Kim et al., 2003), which has greatly improved our understanding of the chemical features of DOM at the molecular level (Reemtsma, 2009; Minor et al., 2014), although it has difficulties with quantitative analysis. Recently, FT-ICR-MS has been used to investigate the molecular transformation of river and ocean DOM induced by sunlight irradiation (Gonsior et al., 2009; Stubbins et al., 2010). The molecular characteristics of photo-resistant, photolabile and photo-produced fractions in Congo River DOM were described by Stubbins et al. (2010).

Characterization of anthropogenic DOM such as the ones derived from wastewater, sewage or farm wastes etc (Meng et al., 2013). at the molecular level using FT-ICR-MS has been very limited (Gonsior et al., 2011; Li et al., 2015; Tseng et al., 2013). In a previous research using FT-ICR-MS, Gonsior et al. (2011) found that DOM in effluent displayed a much more complex molecular diversity than the ones in natural water, notably the presence of an unexpected amount of sulfur-containing molecular formulas. Li et al. (2015) used FT-ICR-MS to further investigate the molecular transformation of DOM in refinery wastewater from water treatment processes. However, clarification of molecular transformation in wastewater- and sludge-derived DOM induced by photochemical or other biogeochemical process has not been achieved.

Sludge is an important sink of engineered nanoparticles. Previous studies have revealed that $\mathrm{TiO}_{2}$ accumulates in dry sludge at concentrations ranging from 1 to $6 \mathrm{~g} \mathrm{Ti} / \mathrm{kg}$ (Kiser et al., 2009; Gottschalk and Nowack, 2011). Furthermore, organic matters are also prone to sequestration in sludge. As a result, the coexistence of nano $\mathrm{TiO}_{2}$ and sludge-derived DOM is widespread. The aim of the present study was to investigate the molecular transformations of natural and anthropogenic DOM under photo-irradiation in the presence of nano $\mathrm{TiO}_{2}$ using ESI-FT-ICR-MS. The results will extend our understanding of the environmental and ecological risk of photoactive nanomaterials such as nano $\mathrm{TiO}_{2}$ as well as the fate of DOM in the environment.

\section{Materials and methods}

\subsection{Peat and sewage sludge dissolved organic matter}

Water-extractable organic matter extracted from a commercially available fen peat (Klasmann, Germany) was selected as the representative of natural DOM (peat DOM, DOM ${ }_{p}$ ), and waterextractable organic matter extracted from sewage sludge (sludgederived DOM, $\mathrm{DOM}_{\mathrm{S}}$ ) generated in a wastewater treatment plant in Beijing was selected as the representative of anthropogenic DOM. Briefly, the DOM was extracted by shaking dry peat or sewage sludge with ultrapure water at a ratio of $1: 10$ for $24 \mathrm{~h}$ at room temperature. The leachate was obtained by centrifugation of the above peat or sewage sludge suspensions at $5000 \mathrm{rpm}$ and filtered through $0.22-\mu \mathrm{m}$ Nylon filters. The extraction procedure was repeated three times. The final $\mathrm{DOM}_{\mathrm{p}}$ and $\mathrm{DOM}_{\mathrm{s}}$ solutions were kept in the dark at $4{ }^{\circ} \mathrm{C}$ until further use.
Structural characteristics and carbon-functional-group contents in $\mathrm{DOM}_{\mathrm{p}}$ and $\mathrm{DOM}_{\mathrm{s}}$ were measured with solid-state ${ }^{13} \mathrm{C}$ NMR using cross-polarization and magic angle spinning (CP/MAS) techniques. Spectra were recorded on a $400 \mathrm{MHz}$ NMR Unity Inova Varian spectrometer using the same method as a previous study (Rodriguez-Zuniga et al., 2008).

\subsection{Photochemical experiment}

A typical photochemical experimental procedure was adopted in this study. Aqueous solutions of DOM, set at $40 \mathrm{mg} \mathrm{L}^{-1} \mathrm{TOC}$, higher than their normal environmental levels, and commercialgrade $\mathrm{TiO}_{2}$ (Aeroxide $\mathrm{P} 25, \quad 80 \%$ anatase and 20\% rutile, $100 \mathrm{mg} \mathrm{L}^{-1}$ ) were put into a $250-\mathrm{mL}$ glass-lined vessel under constant stirring. The $\mathrm{pH}$ of the suspension was adjusted to 7.0 using diluted $\mathrm{HCl}(0.1 \mathrm{M})$ and then equilibrated in the dark under stirring for $2 \mathrm{~h}$ before illumination. The extent of DOM adsorption onto nano- $\mathrm{TiO}_{2}$ was found to be insignificant in the dark control (about $1.2 \%$ of DOC adsorbed) due to the low ratio of nano- $\mathrm{TiO}_{2}$ to DOC loaded. Simulated solar irradiation experiments were performed in a CEL-APR photochemical reactor (Ceaulight, Beijing, China) equipped with a $300 \mathrm{~W}$ xenon lamp placed in a quartz cooling well. An AM 1.5 filter was used to best match the total solar spectrum, with average illuminance of about $1.2 \times 10^{5}$ lux. Dark control samples were processed under the same conditions except for photo-irradiation. At given time intervals, a certain amount of suspension solution was collected, centrifuged and filtered through pre-rinsed $0.22 \mu \mathrm{m}$ Nylon membranes, and the filtered supernatants were used for further analysis. The absorbance spectra of the filtered supernatants from 200-650 were determined using a Shimadzu UV-2600 UV-vis spectrometer. All batch experiments were conducted in triplicate.

\subsection{ESI-FT-ICR-MS analysis}

Selected samples before and after photo-irradiation were further analyzed by ESI-FT-ICR-MS. Sample entrapment and desalination were performed on all the samples by solid phase extraction (SPE) according to Dittmar et al. (2008) using Varian Bond Elute PPL cartridges (500 mg/6 mL). Briefly, the cartridges were rinsed with $6 \mathrm{~mL}$ of methanol (MS grade) and pure water respectively prior to use. The samples were acidified to $\mathrm{pH} 2$ with $\mathrm{HCl}$ (32\%, ultrapure), and then passed through the cartridges by gravity at a flow rate of approximately $2 \mathrm{~mL} \mathrm{~min}^{-1}$. Cartridges were rinsed with three volumes of $0.01 \mathrm{M} \mathrm{HCl}$ for the removal of salts, dried with a stream of $\mathrm{N}_{2}$ and immediately extracted with three volumes of methanol (MS grade). Eluted samples were blow-dried with $\mathrm{N}_{2}$ and kept in the dark at $-20^{\circ} \mathrm{C}$. The extraction efficiencies of $\mathrm{DOM}_{\mathrm{p}}$ and $\mathrm{DOM}_{\mathrm{S}}$ by PPL-based SPE were about $72 \%$ and $61 \%$ according to their TOC recoveries, respectively. Some highly hydrophilic compounds such as carbohydrates and proteins may be lost during SPE (Riedel et al., 2012); therefore, the identified DOM is actually SPEDOM. These dried samples were dissolved in 50:50 methanol/water $(\mathrm{v} / \mathrm{v})$ for ultrahigh resolution mass spectrometry analysis. Ultrahigh resolution mass spectra were acquired using a Bruker SolariX FT-ICR-MS equipped with a 15.0 T superconducting magnet and an ESI irradiation ion source under the same conditions as the previous report (Cao et al., 2015; Lv et al., 2016).

\subsection{Molecular formula assignment}

All possible formulas were identified with Bruker Data Analysis software based on the requirement that the mass error for a given chemical formula between measured mass and calculated mass was $\leq 0.5 \mathrm{ppm}$. Molecular formulas were assigned to peaks with a 
signal-to-noise ratio $(S / N) \geq 6$, according to stringent criteria with elemental combinations of $\mathrm{C}_{5}-{ }_{60} \mathrm{H}_{10}-{ }_{120} \mathrm{O}_{0}-{ }_{40} \mathrm{~N}_{0}-{ }_{2} \mathrm{~S}_{0-2}$. The elemental ratios of $\mathrm{H} / \mathrm{C}<2.4$ and $\mathrm{O} / \mathrm{C}<1.2$ were used as further restrictions for formula calculation. The following parameters for data analysis were calculated according to previous reports (Hughey et al., 2001; Kellerman et al., 2014; Kim et al., 2003; Koch and Dittmar 2006, Stenson et al., 2003): H/C ratio and O/C ratio, parameters for constructing the van Krevelen diagram (Kim et al., 2003); Kendrick mass (KM) and Kendrick mass defect (KMD) in order to identify $\mathrm{CH}_{2}$-homologous molecular formula series (Hughey et al., 2001); and double-bond equivalence (DBE), a measure of the number of double bonds and rings in a molecule (Stenson et al., 2003). The aromaticity index was calculated from formulas according to Koch and Dittmar to estimate the fraction of aromatic and condensed aromatic structures (Koch and Dittmar 2006). Furthermore, four compound groups were delineated by aromaticity index (AI) and $\mathrm{H} / \mathrm{C}$ cutoffs according to Kellerman et al. (2014): combustion-derived condensed polycyclic aromatics (AI > 0.66), vascular plant-derived polyphenols (0.66 > AI >0.5), highly unsaturated and phenolic compounds ( $\mathrm{AI} \leq 0.50$ and $\mathrm{H} /$ $\mathrm{C}<1.5)$, and aliphatic compounds $(2.0 \geq \mathrm{H} / \mathrm{C}>1.5)$.

\section{Results and discussion}

\subsection{Molecular diversity of $\mathrm{DOM}_{p}$ and $\mathrm{DOM}_{S}$}

The molecular characteristics of the initial $\mathrm{DOM}_{\mathrm{p}}$ and $\mathrm{DOM}_{\mathrm{s}}$ were determined by negative ion ESI-FT-ICR-MS (Fig. $1 \mathrm{~A}-\mathrm{E}$ ) and ${ }^{13} \mathrm{C}$ NMR (Fig. 1F). There were $2253 \mathrm{C}_{\mathrm{c}} \mathrm{H}_{\mathrm{h}} \mathrm{O}_{\mathrm{O}} \mathrm{N}_{\mathrm{n}}$ molecular formulas and $2520 \mathrm{C}_{\mathrm{C}} \mathrm{H}_{\mathrm{h}} \mathrm{O}_{\mathrm{O}} \mathrm{N}_{\mathrm{n}} \mathrm{S}_{\mathrm{S}}$ molecular formulas $(\mathrm{S} / \mathrm{N} \geq 6$, in the mass range 200-700 Da) identified in the initial $\mathrm{DOM}_{\mathrm{p}}$ and $\mathrm{DOM}_{\mathrm{s}}$, respectively, after quality assurance filtering by ESI-FT-ICR-MS analysis. Considering the remarkably low S content (about $0.45 \%$ ), the Scontaining molecular formulas were not included in the $\mathrm{DOM}_{\mathrm{p}}$. We can see from Fig. 1 that $\mathrm{DOM}_{\mathrm{S}}$ contained less CHO formulas (24\% for
$\mathrm{DOM}_{\mathrm{S}}$ vs $78 \%$ for $\mathrm{DOM}_{\mathrm{p}}$ ) and more heteroatom formulas (76\% for $\mathrm{DOM}_{\mathrm{s}}$ vs $22 \%$ for $\mathrm{DOM}_{\mathrm{p}}$ ) than did $\mathrm{DOM}_{\mathrm{p}}$, which were likely ascribable to the contributions of microbial and anthropogenic discharge sources (Michael-Kordatou et al., 2015). The mass spectra showed an irregular distribution of masses in $\mathrm{DOM}_{\mathrm{S}}$ compared with those of $\mathrm{DOM}_{\mathrm{p}}$. The intense peaks in the spectra for $\mathrm{DOM}_{\mathrm{s}}$ were associated with $\mathrm{CHOS}$ formulas. The identified formulas of the most intense peaks in $\mathrm{DOM}_{\mathrm{S}}$ corresponded to linear alkyl benzene sulfonates (LAS), which have been found in wastewater at high concentrations, and were also consistent with the molecular characterization of DOM in effluent reported by Gonsior et al. (2011). Magnitude-weighted average formulas of $\mathrm{DOM}_{\mathrm{S}}$ contained lower numbers of $\mathrm{C}$ and $\mathrm{O}$ atoms but higher numbers of $\mathrm{H}, \mathrm{N}$ and $\mathrm{S}$ atoms with higher $\mathrm{H} / \mathrm{C}$, lower degree of unsaturation (DBE) and lower $\mathrm{O} / \mathrm{C}$ than $\mathrm{DOM}_{\mathrm{p}}$ (Table S1). The van Krevelen diagram is often used to provide a visual graphic display of compound distribution (Kim et al., 2003). Combining the aromaticity index ( $\mathrm{AI}_{\text {mod }}$ ) and $\mathrm{H} /$ $\mathrm{C}$, all the identified molecules are divided into four groups according to their location in the van Krevelen diagram (Koch and Dittmar 2006), i.e., condensed polycyclic aromatics (group 1), polyphenols (group 2), highly unsaturated and phenolic compounds (group 3) and aliphatic compounds (group 4) as shown in Fig. 1C-E. The most abundant compounds in $\mathrm{DOM}_{\mathrm{p}}$ and $\mathrm{DOM}_{\mathrm{s}}$ were located in group $3\left(69.8 \%\right.$ and $60.4 \%$ for $\mathrm{DOM}_{\mathrm{p}}$ and $\mathrm{DOM}_{\mathrm{s}}$, respectively); while the second-most abundant compounds were polyphenols (group 2, 21.9\%) in $\mathrm{DOM}_{\mathrm{p}}$ and aliphatic compounds (group $4,30.7 \%$ ) in $\mathrm{DOM}_{\mathrm{s}}$, respectively, which displayed a remarkable difference between $\mathrm{DOM}_{\mathrm{p}}$ and $\mathrm{DOM}_{\mathrm{s}}$. The large amounts of aliphatic compounds in $\mathrm{DOM}_{\mathrm{s}}$ were likely ascribed to the contributions from anthropogenic discharges such as surfactants, fatty acids and their biodegradation products (Gonsior et al., 2011), as well as lipids produced by aerobic micro-organisms (Angerbauer et al., 2008). The low abundance of polyphenol compounds in $\mathrm{DOM}_{\mathrm{s}}$ was likely due to their strong affinity to solids and the high reactivity of phenol groups, which were preferentially removed and
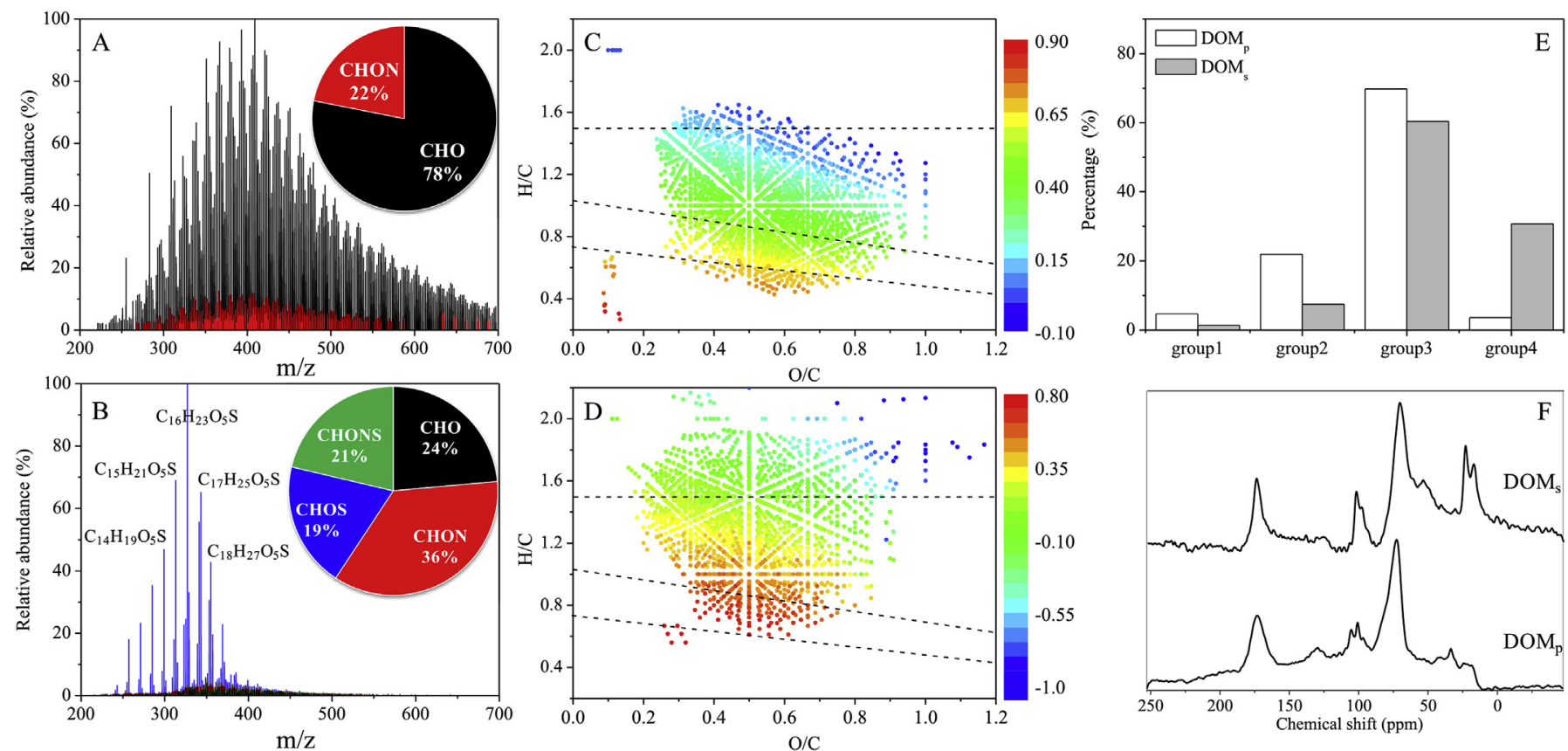

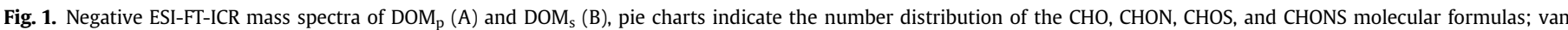

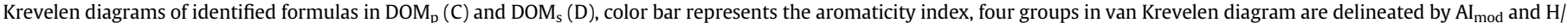

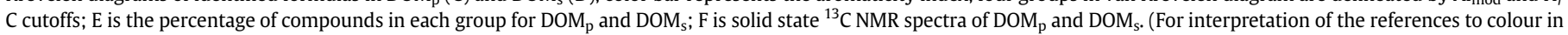
this figure legend, the reader is referred to the web version of this article.) 
degraded during water treatment processes (Bruno et al., 2002; Lara-Martin et al., 2010; Li et al., 2015). In addition, there were more condensed polycyclic aromatics (group 1) in $\mathrm{DOM}_{\mathrm{p}}(4.7 \%$ ) than in $\mathrm{DOM}_{\mathrm{s}}(1.4 \%)$. Solid ${ }^{13} \mathrm{C}$ NMR analysis has frequently been used to quantify the relative distributions of $C$ functional groups, especially for aromatic and aliphatic C in DOM, and was therefore conducted on $\mathrm{DOM}_{\mathrm{s}}$ and $\mathrm{DOM}_{\mathrm{p}}$. The results (Fig. $1 \mathrm{~F}$ and Table S2) show the relative distributions, with more aromatic C (18.8\% vs $4.0 \%$ ) and less aliphatic C (17.2\% vs $33.4 \%$ ) in $\mathrm{DOM}_{\mathrm{p}}$ than DOMs, consistent with the results showing the higher molecular abundance distribution of groups 1 and 2 (rich in aromatic C) and lower molecular abundance distribution of group 4 (rich in alkyl C) in $\mathrm{DOM}_{\mathrm{p}}$ than DOMs, obtained from the van Krevelen diagram.

\subsection{Photo-bleaching and photo-mineralization of DOM affected by $\mathrm{TiO}_{2}$}

Photo-bleaching is caused by the degradation of aromatic and conjugated compounds that have strong light absorbance (Gonsior et al., 2009; Sharpless et al., 2014), while photo-mineralization is due to the complete photooxidation of DOM compounds to $\mathrm{CO}_{2}$ (Ward and Cory, 2016). Fig. 2A and B shows that $98.7 \%$ of $\mathrm{DOM}_{\mathrm{p}}$ and $93.8 \%$ of $\mathrm{DOM}_{\mathrm{s}}$ were photo-bleached (quantified by the loss of $\mathrm{UV}_{254}$ ), while only $75.3 \%$ of $\mathrm{DOM}_{\mathrm{p}}$ and $66.8 \%$ of $\mathrm{DOM}_{\mathrm{S}}$ were photomineralized (quantified by the loss of TOC) after $12 \mathrm{~h}$ of photoirradiation in the presence of nano $\mathrm{TiO}_{2}$. However, control groups without nano $\mathrm{TiO}_{2}$ displayed insignificant changes of TOC and UV-Vis absorbance, indicating negligible photo-degradation of DOM in the absence of nano $\mathrm{TiO}_{2}$. The observed higher percentage of $\mathrm{UV}_{254}$ removal than that of TOC removal indicated that destruction of compounds containing chromophore groups in DOM was easier than the mineralization of DOM, and showed the presence of refractory compounds, either present in the beginning or generated during the photo-degradation (Rodriguez-Zuniga et al., 2008). Similar results were obtained by previous studies on the degradation of DOM by $\mathrm{TiO}_{2}$ photocatalytic oxidation (Liu et al., 2008a, 2008b). In order to further investigate the molecular characteristics of DOM after photo-irradiation, results obtained from ESI-FT-ICR-MS analysis were used to explain the transformation of the individual molecules in DOM during photo-irradiation.

\subsection{Photochemically induced alteration in chemodiversity of DOM}

The van Krevelen diagrams of all molecules in $\mathrm{DOM}_{\mathrm{p}}$ and $\mathrm{DOM}_{\mathrm{s}}$ during photo-irradiation are displayed in Figs. S1 and S2. It seems quite clear that the chemodiversities of $\mathrm{DOM}_{\mathrm{p}}$ and $\mathrm{DOM}_{\mathrm{s}}$ were attenuated after photo-irradiation. Fig. 3A shows the decrements of CHO and CHON molecules in $\mathrm{DOM}_{\mathrm{p}}$ as a function of photoirradiation time. The number of identified molecules decreased significantly with the increase of photo-irradiation time. At the end of $12 \mathrm{~h}$, about $52.7 \%$ of $\mathrm{CHO}$ and $47.3 \%$ of CHON molecules were degraded in solution compared to the initial $\mathrm{DOM}_{\mathrm{p}}$. Much stronger reduction in molecular diversity was observed for $\mathrm{DOM}_{\mathrm{S}}$ than for $\mathrm{DOM}_{\mathrm{p}}$. About $82.1 \%$ of $\mathrm{CHO}$ and $84.8 \%$ of $\mathrm{CHON}$ molecules were degraded in solution compared with molecules in the initial $\mathrm{DOM}_{\mathrm{s}}$. CHONS molecules and especially CHOS molecules, which had high intensities, were almost completely degraded at the end of $12 \mathrm{~h}$ (Fig. 3B), implying that S-containing compounds in $\mathrm{DOM}_{\mathrm{s}}$ were easily degraded by $\mathrm{TiO}_{2}$ photocatalytic oxidation.

Fig. $3 \mathrm{C}$ and D further display the alteration of molecular components of compounds in $\mathrm{DOM}_{\mathrm{p}}$ and $\mathrm{DOM}_{\mathrm{s}}$, respectively. Fig. $3 \mathrm{~B}$ shows that the proportion of condensed polycyclic aromatics and polyphenols (compounds in group 1 and 2) in $\mathrm{DOM}_{\mathrm{p}}$ decreased drastically (from $4.7 \%$ to $0 \%$ for group 1 and from $21.9 \%$ to $1.7 \%$ for group 2) within $12 \mathrm{~h}$ photo-irradiation, while the proportion of highly unsaturated and phenolic compounds (compounds in group 3 ) and aliphatic compounds (compounds in group 4) in $\mathrm{DOM}_{\mathrm{p}}$ increased (from $69.8 \%$ to $88.1 \%$ for group 3 and from $3.6 \%$ to $10.2 \%$ for group 4, respectively). The decreases in the compounds in groups 1 and 2 after photo-irradiation indicated that condensed polycyclic aromatics and polyphenols were more prone to photocatalytic transformation, which is in agreement with the UV-vis absorbance results, since the compounds degraded during photoirradiation were the condensed polycyclic aromatics and polyphenols that had strong UV absorbance. Similar alterations were observed in Congo River DOM after 57 days of solar radiation, which indicated that aromatic compounds were the most photolabile, while aliphatic compounds dominated the photoproduced DOM (Stubbins et al., 2010). Similar to $\mathrm{DOM}_{\mathrm{p}}$, the condensed polycyclic aromatics and polyphenols in $\mathrm{DOM}_{\mathrm{s}}$ (1.4\% for group 1 and $7.5 \%$ for group 2, respectively) were degraded completely within $12 \mathrm{~h}$ of photo-irradiation, while the proportion of highly unsaturated and phenolic compounds in $\mathrm{DOM}_{\mathrm{S}}$ (compounds in group 3) increased from $60.4 \%$ to $87.9 \%$ (Fig. 3D). In contrast to $\mathrm{DOM}_{\mathrm{p}}$, the proportion of aliphatic compounds (compounds in group 4) in $\mathrm{DOM}_{\mathrm{s}}$ decreased from $30.7 \%$ to $12.1 \%$, mainly due to the high amount of CHOS compounds in $\mathrm{DOM}_{\mathrm{s}}$. Sixty-five percent of CHOS compounds in $\mathrm{DOM}_{\mathrm{S}}$ were aliphatics according to the classification based on the van Krevelen diagram mentioned above, however almost all of them were degraded after $12 \mathrm{~h}$ of photocatalytic degradation.
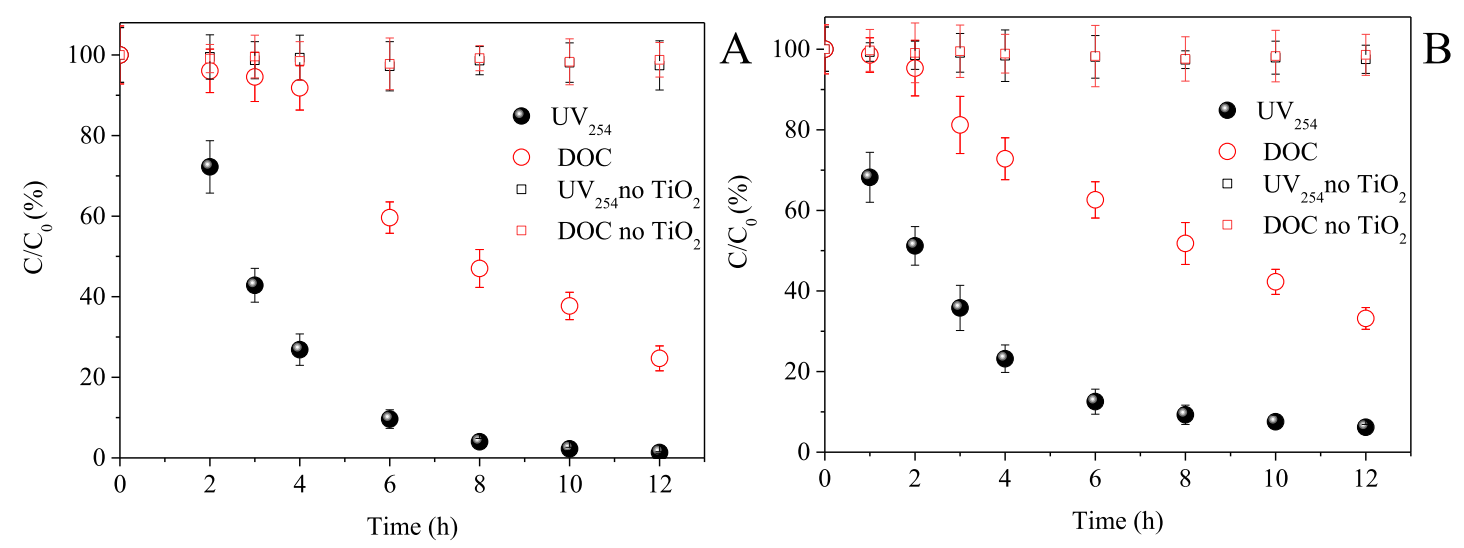

Fig. 2. Decreases in $\mathrm{DOC}$ and $\mathrm{UV}_{254}$ during $\mathrm{TiO}_{2}$ photocatalytic transformation of $\mathrm{DOM}_{\mathrm{p}}(\mathrm{A})$ and $\mathrm{DOM}_{\mathrm{s}}(\mathrm{B})$ in the presence and absence of $\mathrm{TiO}$. 

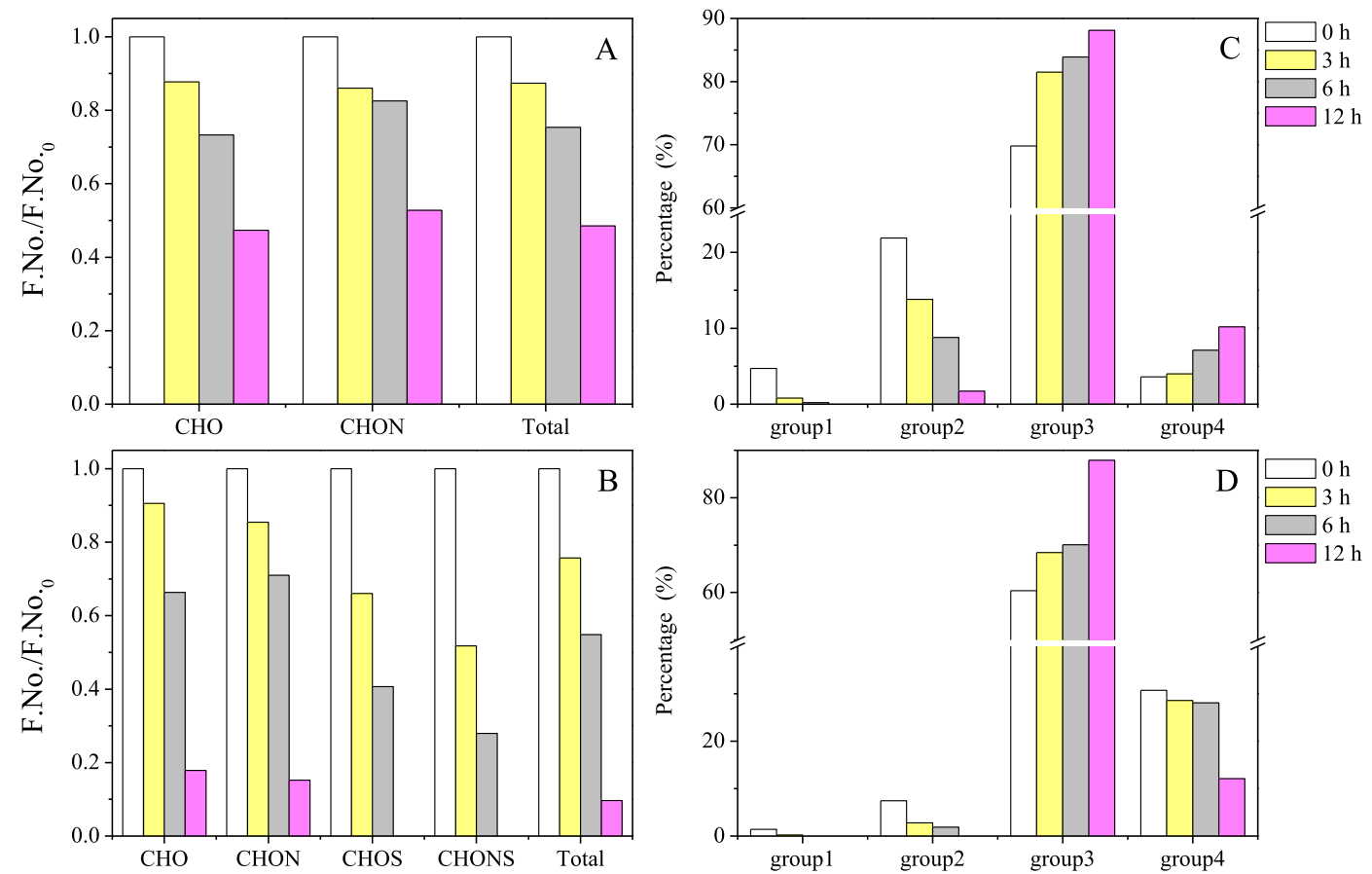

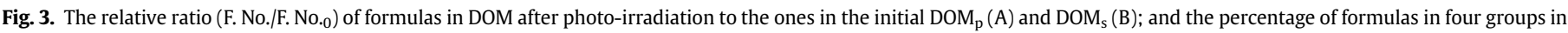
$\mathrm{DOM}_{\mathrm{p}}(\mathrm{C})$ and $\mathrm{DOM}_{\mathrm{s}}(\mathrm{D})$ after photo-irradiation.

\subsection{Photochemical alteration of molecular characteristics of DOM}

Figs. 4 and 5 further display the detailed molecular transformation of compounds in $\mathrm{DOM}_{\mathrm{p}}$ and $\mathrm{DOM}_{\mathrm{s}}$ during photoirradiation. The percentage of high-molecular-weight compounds decreased, while that of low-molecular-weight compounds increased during photo-irradiation for both $\mathrm{DOM}_{\mathrm{p}}$ and $\mathrm{DOM}_{s}$, although almost all the CHOS and CHONS compounds in $\mathrm{DOM}_{S}$ disappeared after $12 \mathrm{~h}$ of photocatalytic transformation (Figs. 4A, E and $5 \mathrm{~A}, \mathrm{E}, \mathrm{I}$ and $\mathrm{M}$ ). This alteration of molecular weight was in agreement with the results obtained by Stubbins et al. (2010). Previous study using SEC to fractionate DOM indicated that $\mathrm{TiO}_{2}$ photocatalytic oxidation preferentially degraded the highmolecular-weight fractions of DOM (Liu et al., 2008b). Similar results were also obtained by the photochemical alteration of DOM without catalyst using SEC (Brinkmann et al., 2003; Lou and Xie, 2006). However, it is necessary to note that what are detected by SEC are actually the weights of molecular clusters but not of single molecules. Therefore, the molecular weight detected by SEC is much larger than that detected by FT-ICR-MS in this study. Reduction of high-molecular-weight fractions of DOM detected by SEC is more likely ascribed to the breakdown of molecular clusters induced by photo degradation.

Besides the consistent alteration of molecular weight, extensive alterations in molecular characteristics of $\mathrm{DOM}_{\mathrm{p}}$ and $\mathrm{DOM}_{\mathrm{s}}$ were further observed after $\mathrm{TiO}_{2}$ photocatalytic transformation. First, the alterations of molecular weight, $\mathrm{H} / \mathrm{C}, \mathrm{O} / \mathrm{C}, \overline{\mathrm{OS}}_{\mathrm{C}}$ and $\mathrm{DBE}$ of $\mathrm{CHON}$ compounds in $\mathrm{DOM}_{\mathrm{p}}$ during photo-irradiation were consistent
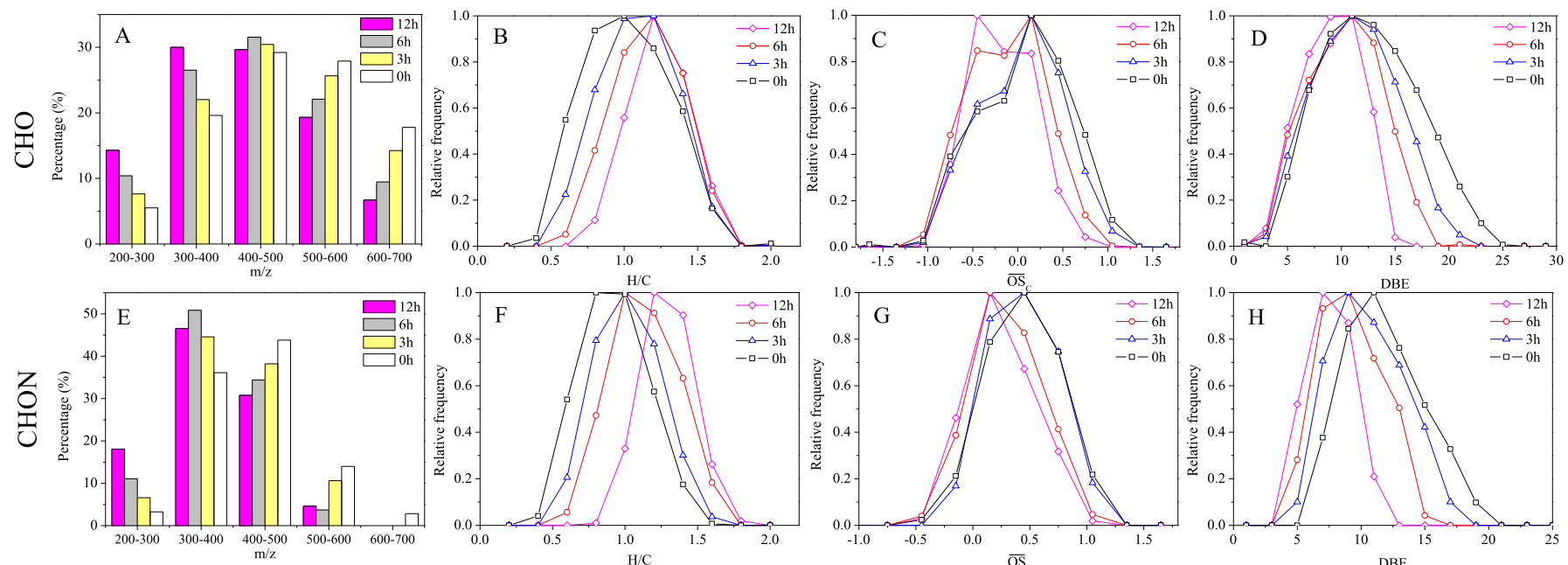

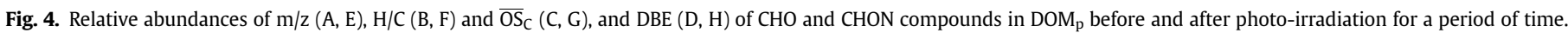



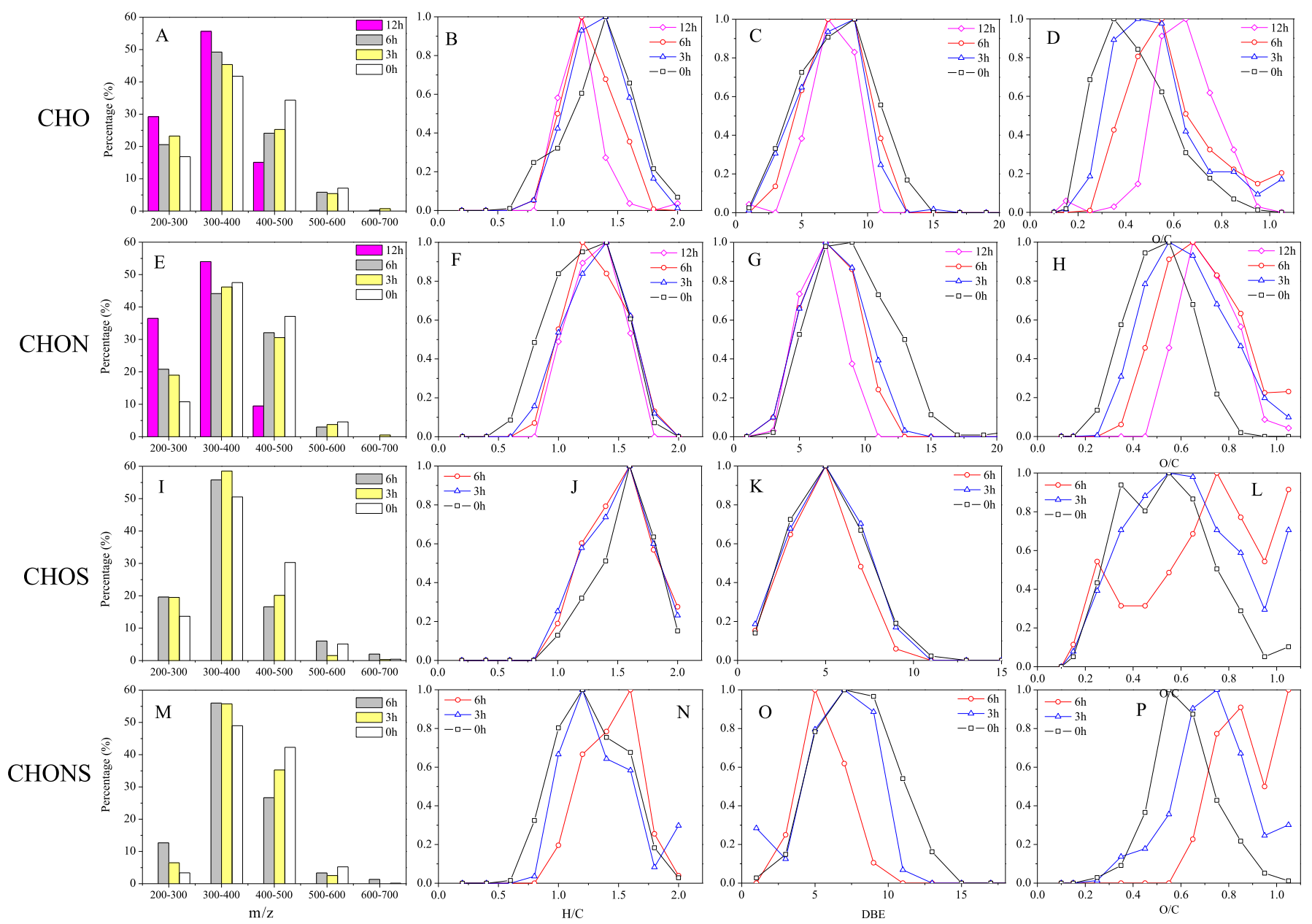

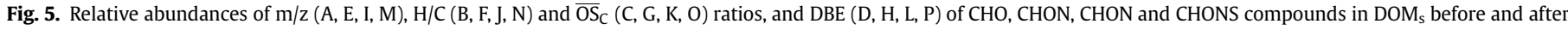
photo-irradiation for a period of time.

with those of $\mathrm{CHO}$ compounds (Fig. 4), which indicated that the influence of heteroatom $\mathrm{N}$ on the photocatalytic transformation of $\mathrm{DOM}_{\mathrm{p}}$ was insignificant. In particular, as shown in Fig. $4 \mathrm{~B}$ and $\mathrm{F}$, the $\mathrm{H} / \mathrm{C}$ ratio of $\mathrm{CHO}$ and $\mathrm{CHON}$ compounds in $\mathrm{DOM}_{\mathrm{p}}$ increased, while the DBE values of $\mathrm{CHO}$ and $\mathrm{CHON}$ compounds decreased with the increase of photo-irradiation time, which implied that the carbon unsaturation degree in compounds was decreased by $\mathrm{TiO}_{2}$ photocatalytic transformation. The decrease in carbon unsaturation degree may be caused by cleavage reactions of rings or double bonds, as supported by the observation of the attenuation of compounds such as condensed polycyclic aromatics and polyphenols during photo-irradiation as mentioned above (Fig. 3). The oxidation state of carbon $\left(\mathrm{OS}_{\mathrm{C}}\right)$ is defined as the charge a carbon atom would take if it were to lose all electrons in bonds with more electronegative atoms, but gain all electrons in bonds with less electronegative atoms (Kroll et al., 2011). The electronegativity of atoms follows the order $\mathrm{O}>\mathrm{C}>\mathrm{H}$, in which a $\mathrm{C}=\mathrm{O}$ double bond (such as carboxyl and carbonyl groups) contributes $+2 \mathrm{OS}_{\mathrm{C}}$, and a $\mathrm{C}-\mathrm{O}$ single bond (such as alcohol and ether groups) contributes $+1 \mathrm{OS}_{\mathrm{C}}$, while a $\mathrm{C}-\mathrm{H}$ bond contributes $-10 S_{C}$, respectively. As shown in Fig. $4 \mathrm{C}$ and $\mathrm{G}$, the average carbon oxidation state $\left(\overline{\mathrm{OS}}_{\mathrm{C}}\right)$ of $\mathrm{CHO}$ and $\mathrm{CHON}$ compounds in $\mathrm{DOM}_{\mathrm{p}}$ decreased with the increase of photo-irradiation time, which implied that compounds with high $\overline{\mathrm{OS}}_{\mathrm{C}}$, especially those containing a $\mathrm{C}=\mathrm{O}$ double bond, were preferentially degraded during $\mathrm{TiO}_{2}$ photocatalytic oxidation, for example, by decarboxylation, and transformed to the final product $\mathrm{CO}_{2}$. As a result, about
$75 \%$ of the total organic carbon of $\mathrm{DOM}_{\mathrm{p}}$ was reduced. However, insignificant decrease of the $\mathrm{O} / \mathrm{C}$ ratio of compounds in $\mathrm{DOM}_{\mathrm{p}}$ was observed during photo-irradiation (Fig. S3), which indicated the generation of newly formed oxygen-containing groups by $\mathrm{TiO}_{2}$ photocatalytic oxidation. For example, some compounds with very high $\mathrm{O} / \mathrm{C}$ and $\mathrm{H} / \mathrm{C}$ ratios (distributed at the upper right of van Krevelen diagrams), mainly grouped as oxidized polysaccharides, were produced (Fig. S5). The photo-resistant compounds after $12 \mathrm{~h}$ photo-irradiation were mainly those with formulas containing high $\mathrm{H} / \mathrm{C}$ and lower $\overline{\mathrm{OS}}_{\mathrm{C}}$, DBE and MW. Because photocatalytic oxidation induced obvious decarboxylation of compounds, the O-containing groups in photo-resistant compounds were thought to be dominated by hydroxyl and ether groups.

As shown in Fig. 5, the $\mathrm{H} / \mathrm{C}$ ratio of $\mathrm{CHO}$ and $\mathrm{CHOS}$ compounds in $\mathrm{DOM}_{\mathrm{S}}$ decreased, while it increased for the CHON and CHONS compounds with the increase of photo-irradiation time. The DBE value for CHON and CHONS compounds decreased with the increase of photo-irradiation time, although within a narrow range of DBE value, while little change was observed for the average DBE value of $\mathrm{CHO}$ and $\mathrm{CHOS}$ compounds. Completely opposite to $\mathrm{DOM}_{\mathrm{p}}$, the $\overline{\mathrm{OS}}_{\mathrm{C}}$ of $\mathrm{CHO}, \mathrm{CHON}, \mathrm{CHOS}$ and CHONS compounds in $\mathrm{DOM}_{\mathrm{S}}$ increased with the increase of photo-irradiation time, and consistent changes were observed for the $\mathrm{O} / \mathrm{C}$ of all the compounds (shown in Fig. S3). In summary, alterations in molecular characteristics were consistent for $\mathrm{CHO}$ and $\mathrm{CHOS}$ compounds and were opposite for CHON and CHONS compounds in $\mathrm{DOM}_{s}$, which was 
different from the molecular transformations of $\mathrm{DOM}_{\mathrm{p}}$. Compared to $\mathrm{DOM}_{\mathrm{p}}, \mathrm{DOM}_{\mathrm{s}}$ contained less aromatic $\mathrm{C}$ and more aliphatic $\mathrm{C}$ (as shown by the higher $\mathrm{H} / \mathrm{C}_{\mathrm{w}}$ and lower $\mathrm{DBE}_{\mathrm{w}}$ in Table $\mathrm{S} 1$, and ${ }^{13} \mathrm{C} \mathrm{NMR}$ results in Table $\mathrm{S} 2$ ) with lower oxidation degree (indicated by the lower $\mathrm{O} / \mathrm{C}_{\mathrm{w}}$ and $\overline{\mathrm{OS}}_{\mathrm{Cw}}$ in Table $\mathrm{S} 1$ ). Furthermore, the low $\mathrm{O} / \mathrm{C}_{\mathrm{w}}$ and negative $\overline{\mathrm{OS}}_{\mathrm{Cw}}$ of compounds in $\mathrm{DOM}_{\mathrm{s}}$ implied they contained fewer oxygenic groups, especially carbonyl and/or carboxylic groups, than compounds in $\mathrm{DOM}_{\mathrm{p}}$, which was further confirmed by ${ }^{13} \mathrm{C}$ NMR as shown in Table S2. Therefore, direct decarboxylation induced by $\mathrm{TiO}_{2}$ photocatalytic oxidation of compounds in $\mathrm{DOM}_{\mathrm{S}}$ was limited. Instead, unstable moieties such as unsaturated double bonds and alkyl side chains were likely to be oxidized by $\mathrm{TiO}_{2}$ photocatalytic transformation, resulting in the increase of the $\mathrm{O} / \mathrm{C}_{\mathrm{w}}$ and $\overline{\mathrm{OS}}_{\mathrm{Cw}}$ of compounds (Tran et al., 2006).

\section{Conclusions}

In the present study, ESI-FT-ICR-MS was employed to determine the molecular transformations of peat-derived $\mathrm{DOM}\left(\mathrm{DOM}_{\mathrm{p}}, \mathrm{a}\right.$ representative of natural DOM) and sludge-derived DOM $\left(\mathrm{DOM}_{\mathrm{s}}\right.$, a representative of anthropogenic DOM) under photo-irradiation as affected by nano $\mathrm{TiO}_{2}$. The results indicated that $\mathrm{DOM}_{\mathrm{p}}$ and $\mathrm{DOM}_{\mathrm{s}}$ had very different chemical and molecular composition. $\mathrm{DOM}_{\mathrm{s}}$ contained more heteroatom formulas with lower aromaticity, higher aliphaticity and lower carbon oxidation state than did $\mathrm{DOM}_{\mathrm{p}}$. In the presence of nano $\mathrm{TiO}_{2}$, photo-irradiation enhanced the consumption of DOC and remarkably reduced the molecular diversity of DOM within several hours. Compounds with high molecular weight and/or aromaticity moieties and/or low $\mathrm{O} / \mathrm{C}$ ratio were preferentially degraded by $\mathrm{TiO}_{2}$ photocatalysis in both $\mathrm{DOM}_{\mathrm{p}}$ and $\mathrm{DOM}_{\mathrm{s}}$, while some oxidized molecules with low aromaticity were produced. The heteroatom $\mathrm{N}$ in compounds had little or no influence on the photocatalytic transformation of both kinds of DOM, while heteroatom S-containing compounds in $\mathrm{DOM}_{\mathrm{S}}(\mathrm{CHOS}$ and CHONS compounds) were degraded more easily than $\mathrm{CHO}$ and CHON compounds. Comparing the two DOM, the average carbon oxidation state was reduced in $\mathrm{DOM}_{\mathrm{p}}$ but increased in $\mathrm{DOM}_{\mathrm{s}}$, likely due to the different $\mathrm{O}$ abundance in the two types of DOM, especially the contents of carboxyl moieties in compounds in the two DOM. The present study revealed the influences of photoactive nanomaterials such as nano $\mathrm{TiO}_{2}$ on the molecular transformation of DOM. Such effects are beneficial for the removal of anthropogenic DOM, but they will attenuate the molecular diversity of natural DOM in waters. Considering the fact that more and more photoactive nanoparticles will be released into waters, more attention should be paid to their subsequent impacts on the photocatalytic transformation of DOM in aquatic systems. Particularly, further research is needed to address this issue at environmentally relevant concentrations and conditions, and field studies are highly encouraged.

\section{Acknowledgments}

This work was funded by National Key Research and Development Program of China (2016YFA0203102), the 973 Program of China (Grant 2014CB441102), the Strategic Priority Research Program of the Chinese Academy of Sciences (Grant XDB14020202), and the National Natural Science Foundation of China (Projects 21407161, 21537005 and 21621064).

\section{Appendix B. Supplementary data}

Supplementary data related to this article can be found at http:// dx.doi.org/10.1016/j.watres.2017.08.051.

\section{References}

Adam, V., Loyaux-Lawniczak, S., Labille, J., Galindo, C., del Nero, M., Gangloff, S., Weber, T., Quaranta, G., 2016. Aggregation behaviour of $\mathrm{TiO}_{2}$ nanoparticles in natural river water. J. Nanopart. Res. 18 (1), 1-11.

Aiken, G.R., Hsu-Kim, H., Ryan, J.N., 2011. Influence of dissolved organic matter on the environmental fate of metals, nanoparticles, and colloids. Environ. Sci. Technol. 45 (8), 3196-3201.

Angerbauer, C., Siebenhofer, M., Mittelbach, M., Guebitz, G.M., 2008. Conversion of sewage sludge into lipids by Lipomyces starkeyi for biodiesel production. Bioresour. Technol. 99 (8), 3051-3056.

Brinkmann, T., Horsch, P., Sartorius, D., Frimmel, F.H., 2003. Photoformation of lowmolecular-weight organic acids from brown water dissolved organic matter. Environ. Sci. Technol. 37 (18), 4190-4198.

Bruno, F., Curini, R., Di Corcia, A., Fochi, I., Nazzari, M., Samperi, R., 2002. Determination of surfactants and some of their metabolites in untreated and anaerobically digested sewage sludge by subcritical water extraction followed by liquid chromatography-mass spectrometry. Environ. Sci. Technol. 36 (19), 4156-4161.

Cao, D., Huang, H., Hu, M., Cui, L., Geng, F., Rao, Z., Niu, H., Cai, Y., Kang, Y., 2015. Comprehensive characterization of natural organic matter by MALDI- and ESIFourier transform ion cyclotron resonance mass spectrometry. Anal. Chim. Acta $866,48-58$

Dittmar, T., Koch, B., Hertkorn, N., Kattner, G., 2008. A simple and efficient method for the solid-phase extraction of dissolved organic matter (SPE-DOM) from seawater. Limnol. Oceanogr.-Meth. 6, 230-235.

Domingos, R.F., Tufenkji, N., Wilkinson, K.J., 2009. Aggregation of titanium dioxide nanoparticles: role of a fulvic acid. Environ. Sci. Technol. 43 (5), 1282-1286.

Eggins, B.R., Palmer, F.L., Byrne, J.A., 1997. Photocatalytic treatment of humic substances in drinking water. Water Res. 31 (5), 1223-1226.

Gonsior, M., Peake, B.M., Cooper, W.T., Podgorski, D., D'Andrilli, J., Cooper, W.J., 2009. Photochemically induced changes in dissolved organic matter identified by ultrahigh resolution Fourier transform ion cyclotron resonance mass spectrometry. Environ. Sci. Technol. 43 (3), 698-703.

Gonsior, M., Zwartjes, M., Cooper, W.J., Song, W., Ishida, K.P., Tseng, L.Y., Jeung, M.K., Rosso, D., Hertkorn, N., Schmitt-Kopplin, P., 2011. Molecular characterization of effluent organic matter identified by ultrahigh resolution mass spectrometry. Water Res. 45 (9), 2943-2953.

Gottschalk, F., Nowack, B., 2011. The release of engineered nanomaterials to the environment. J. Environ. Monit. 13 (5), 1145-1155.

Gottschalk, F., Scholz, R.W., Nowack, B., 2010. Probabilistic material flow modeling for assessing the environmental exposure to compounds: methodology and an application to engineered nano-TiO 2 particles. Environ. Modell. Softw. 25 (3), $320-332$.

Gottschalk, F., Sonderer, T., Scholz, R.W., Nowack, B., 2009. Modeled environmental concentrations of engineered nanomaterials $\left(\mathrm{TiO}_{2}, \mathrm{ZnO}, \mathrm{Ag}, \mathrm{CNT}\right.$, Fullerenes) for different regions. Environ. Sci. Technol. 43 (24), 9216-9222.

Hughey, C.A., Hendrickson, C.L., Rodgers, R.P., Marshall, A.G., Qian, K.N., 2001. Kendrick mass defect spectrum: a compact visual analysis for ultrahighresolution broadband mass spectra. Anal. Chem. 73 (19), 4676-4681.

Kellerman, A.M., Dittmar, T., Kothawala, D.N., Tranvik, L.J., 2014. Chemodiversity of dissolved organic matter in lakes driven by climate and hydrology. Nat. Commun. 5, 3804.

Kim, S., Kramer, R.W., Hatcher, P.G., 2003. Graphical method for analysis of ultrahigh-resolution broadband mass spectra of natural organic matter, the van Krevelen diagram. Anal. Chem. 75 (20), 5336-5344.

Kiser, M.A., Westerhoff, P., Benn, T., Wang, Y., Perez-Rivera, J., Hristovski, K., 2009. Titanium nanomaterial removal and release from wastewater treatment plants. Environ. Sci. Technol. 43 (17), 6757-6763.

Klaine, S.J. Alvarez, PJ. Batley, G.E., Fernandes, T.F. Handy, R.D., Lyon, D.Y. Mahendra, S., McLaughlin, M.J., Lead, J.R., 2008. Nanomaterials in the environment: behavior, fate, bioavailability, and effects. Environ. Toxicol. Chem. 27 (9), 1825-1851.

Koch, B.P., Dittmar, T., 2006. From mass to structure: an aromaticity index for highresolution mass data of natural organic matter. Rapid Commun. Mass Spectrom. 20 (5), 926-932.

Kroll, J.H., Donahue, N.M., Jimenez, J.L, Kessler, S.H., Canagaratna, M.R. Wilson, K.R. Altieri, K.E., Mazzoleni, L.R., Wozniak, A.S., Bluhm, H., Mysak, E.R., Smith, J.D., Kolb, C.E., Worsnop, D.R., 2011. Carbon oxidation state as a metric for describing the chemistry of atmospheric organic aerosol. Nat. Chem. 3 (2), 133-139.

Lara-Martin, P.A., Gomez-Parra, A., Sanz, J.L., Gonzalez-Mazo, E., 2010. Anaerobic degradation pathway of linear Alkylbenzene sulfonates (LAS) in sulfatereducing marine sediments. Environ. Sci. Technol. 44 (5), 1670-1676.

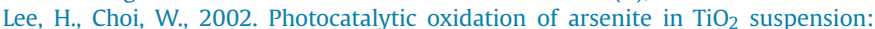
kinetics and mechanisms. Environ. Sci. Technol. 36 (17), 3872-3878.

Li, X.Z., Fan, C.M., Sun, Y.P., 2002. Enhancement of photocatalytic oxidation of humic acid in $\mathrm{TiO}_{2}$ suspensions by increasing cation strength. Chemosphere 48 (4), 453-460.

Li, Y.Y., Fang, Z., He, C., Zhang, Y.H., Xu, C.M., Chung, K.H., Shi, Q., 2015. Molecular characterization and transformation of dissolved organic matter in refinery wastewater from water treatment processes: characterization by Fourier transform ion cyclotron resonance mass spectrometry. Energy Fuel 29 (11), 6956-6963.

Liu, S., Lim, M., Fabris, R., Chow, C., Chiang, K., Drikas, M., Amal, R., 2008a. Removal 
of humic acid using $\mathrm{TiO}_{2}$ photocatalytic process-Fractionation and molecular weight characterisation studies. Chemosphere 72 (2), 263-271.

Liu, S., Lim, M., Fabris, R., Chow, C., Drikas, M., Amal, R., 2008b. TiO(2) photocatalysis of natural organic matter in surface water: impact on trihalomethane and haloacetic acid formation potential. Environ. Sci. Technol. 42 (16), 6218-6223.

Lou, T., Xie, H., 2006. Photochemical alteration of the molecular weight of dissolved organic matter. Chemosphere 65 (11), 2333-2342.

Luo, Z., Wang, Z., Li, Q., Pan, Q., Yan, C., 2010. Effects of titania nanoparticles on phosphorus fractions and its release in resuspended sediments under UV irradiation. J. Hazard. Mater. 174 (1-3), 477-483.

Lv, J., Zhang, S., Wang, S., Luo, L., Cao, D., Christie, P., 2016. Molecular-scale investigation with ESI-FT-ICR-MS on fractionation of dissolved organic matter induced by adsorption on iron oxyhydroxides. Environ. Sci. Technol. 50 (5), 2328-2336.

Meng, F., Huang, G., Yang, X., Li, Z., Li, J., Cao, J., Wang, Z., Sun, L., 2013. Identifying the sources and fate of anthropogenically impacted dissolved organic matter (DOM) in urbanized rivers. Water Res. 47 (14), 5027-5039.

Michael-Kordatou, I., Michael, C., Duan, X., He, X., Dionysiou, D.D., Mills, M.A., FattaKassinos, D., 2015. Dissolved effluent organic matter: characteristics and potential implications in wastewater treatment and reuse applications. Water Res. $77,213-248$.

Minor, E.C., Swenson, M.M., Mattson, B.M., Oyler, A.R., 2014. Structural characterization of dissolved organic matter: a review of current techniques for isolation and analysis. Environ. Sci. Proc. Impac. 16 (9), 2064-2079.

Nowack, B., Bucheli, T.D., 2007. Occurrence, behavior and effects of nanoparticles in the environment. Environ. Pollut. 150 (1), 5-22.

Pena, M., Meng, X.G., Korfiatis, G.P., Jing, C.Y., 2006. Adsorption mechanism of arsenic on nanocrystalline titanium dioxide. Environ. Sci. Technol. 40 (4), 1257-1262.

Reemtsma, T., 2009. Determination of molecular formulas of natural organic matter molecules by (ultra-) high-resolution mass spectrometry status and needs. J. Chromatogr. A 1216 (18), 3687-3701.

Riedel, T., Biester, H., Dittmar, T., 2012. Molecular fractionation of dissolved organic matter with metal salts, Environ. Sci. Technol. 46 (8), 4419-4426.

Robichaud, C.O., Uyar, A.E., Darby, M.R., Zucker, L.G., Wiesner, M.R., 2009. Estimates of upper bounds and trends in nano-TiO 2 production as a basis for exposure assessment. Environ. Sci. Technol. 43 (12), 4227-4233.

Rodriguez-Zuniga, U.F., Milori, D.M., da Silva, W.T., Martin-Neto, L., Oliveira, L.C., Rocha, J.C., 2008. Changes in optical properties caused by UV-irradiation of aquatic humic substances from the amazon river basin: seasonal variability evaluation. Environ. Sci. Technol. 42 (6), 1948-1953.

Sharpless, C.M., Aeschbacher, M., Page, S.E., Wenk, J., Sander, M., McNeill, K., 2014 Photooxidation-induced changes in optical, electrochemical, and photochemical properties of humic substances. Environ. Sci. Technol. 48 (5), 2688-2696.

Stenson, A.C. Marshall, A.G. Cooper, W.T, 2003. Exact masses and chemical formulas of individual Suwannee River fulvic acids from ultrahigh resolution electrospray ionization Fourier transform ion cyclotron resonance mass spectra. Anal. Chem. 75 (6), 1275-1284.

Stubbins, A., Spencer, R.G.M., Chen, H.M., Hatcher, P.G., Mopper, K., Hernes, P.J., Mwamba, V.L., Mangangu, A.M., Wabakanghanzi, J.N., Six, J., 2010. Illuminated darkness: molecular signatures of Congo River dissolved organic matter and its photochemical alteration as revealed by ultrahigh precision mass spectrometry. Limnol. Oceanogr. 55 (4), 1467-1477.

Tran, H., Scott, J., Chiang, K., Amal, R., 2006. Clarifying the role of silver deposits on titania for the photocatalytic mineralisation of organic compounds. J. Photoch. Photobio. A 183 (1-2), 41-52.

Troester, M., Brauch, H.J., Hofmann, T., 2016. Vulnerability of drinking water supplies to engineered nanoparticles. Water Res. 96, 255-279.

Tseng, L.Y., Gonsior, M., Schmitt-Kopplin, P., Cooper, W.., Pitt, P., Rosso, D., 2013. Molecular characteristics and differences of effluent organic matter from parallel activated sludge and integrated fixed-film activated sludge (IFAS) processes. Environ. Sci. Technol. 47 (18), 10277-10284.

Ward, C.P., Cory, R.M., 2016. Complete and partial photo-oxidation of dissolved organic matter draining permafrost soils. Environ. Sci. Technol. 50 (7), 3545-3553.

Wiszniowski, J., Robert, D., Surmacz-Gorska, J., Miksch, K., Weber, J.V., 2003. Photocatalytic mineralization of humic acids with $\mathrm{TiO}_{2}$ : effect of $\mathrm{pH}$, sulfate and chloride anions. Int. J. Photoenergy 5 (2), 69-74.

Wu, Q. Li, C., Wang W. He, T., Hu, H., Du, Y., Wang, T., 2016. Removal of fluorescence and ultraviolet absorbance of dissolved organic matter in reclaimed water by solar light. J. Environ. Sci. (China) 43, 118-127.

Zhang, Z.H., Yuan, Y., Shi, G.Y., Fang, Y.J., Liang, L.H., Ding, H.C., Jin, L.T., 2007. Photoelectrocatalytic activity of highly ordered $\mathrm{TiO}_{2}$ nanotube arrays electrode for azo dye degradation. Environ. Sci. Technol. 41 (17), 6259-6263.

Zhu, M., Wang, H., Keller, A.A., Wang, T., Li, F., 2014. The effect of humic acid on the aggregation of titanium dioxide nanoparticles under different $\mathrm{pH}$ and ionic strengths. Sci. Total Environ. 487, 375-380. 